\title{
ASSESSMENT OF CYCLIC DUCTILE ENDURANCE OF STRUCTURAL STEEL MEMBERS
}

\author{
C.W.K. Hyland ${ }^{1, *}$, W.G. Ferguson ${ }^{2}$ and J.W. Butterworth ${ }^{3}$ \\ ${ }^{I}$ Secretary Manager, Steel Construction New Zealand Inc., PO Box 76403, Manukau City 2241, New Zealand \\ Phone: +64-9-262-6680 Fax: +64-9-263-5638 \\ *(Corresponding author: E-mail: clark.hyland@scnz.org) \\ ${ }^{2}$ Professor of Chemical \& Materials Engineering, University of Auckland, Private Bag 92019, \\ Auckland 1061, New Zealand \\ Phone: +64-9-373-7599 Ext 88133 Fax: +64-9-373-7463 \\ ${ }^{3}$ Associate Professor of Civil and Environmental Engineering, University of Auckland, Private Bag 92019, \\ Auckland 1061, New Zealand \\ Phone: +64-9-373-7599 Ext 88154 Fax: +64-9-373-7462
}

Received: 4 May 2007; Revised: 31 August 2007; Accepted: 18 September 2007

\begin{abstract}
This paper describes a new method using Crack Tip Opening Displacement (CTOD) testing in conjunction with a relatively simple elasto-plastic finite element analysis to assess the likelihood of fast running or slow stable fracture during monotonic and cyclic loading of steel members. The similitude relationship between monotonic and cyclic displacement ductility is then used to assess cyclic endurance of the steel member. The fracture toughness of steel defined by the critical specific work of fracture $R_{c}$ of the steel is determined from CTOD specimens making allowance for remote plastic flow. A finite element model is used to assess elastic compliance of a cracked bar with varying lengths of cracks as well as to assess the inelastic displacement of the bar at calculated cracking loads. Failure limit state surfaces comprising plastic hinging, plastic over-strength and cracking limits are plotted in 3-D surfaces to identify the characteristics of how fracture behaviour changes dramatically as the strain hardening and crack length increases.
\end{abstract}

Keywords: Specific work of fracture, fracture toughness, structural ductility, cyclic endurance, seismic, finite element analysis, CTOD

\section{INTRODUCTION}

This paper describes a cyclic plastic endurance assessment method developed from the findings of an experimental and theoretical study by Hyland, Ferguson and Butterworth [1]. The study was undertaken to investigate the development of running fracture in large structural steel assemblies in building structures subjected to earthquake loading. A specific work of fracture approach was found to be effective in conjunction with elasto-plastic finite element modelling of members in assessing the mode of fracture and the expected endurance of members under cyclic plastic loading.

The determination of the specific work of fracture properties based on the use of small scale side grooved CTOD specimens is first described. The effect of remote plastic flow, strain hardening and aging is considered in determining the critical specific work of fracture value $\mathrm{R}_{\mathrm{c}}$. The assessment of the governing fracture condition is made by evaluating the plastic hinge, strain hardened and running fracture limit states plotted as surfaces to determine which governs as the material strain hardens under cyclic loading.

The similitude relationship is then used to assess the expected endurance of an example simply supported beam under plastic cyclic loads of constant amplitude. The approach is extended into a variable amplitude case equivalent to an ATC-24 loading regime by use of a Palmgren-Miner summation method. 


\section{DETERMINATION OF FRACTURE TOUGHNESS BASED ON CRITICAL SPECIFIC WORK OF FRACTURE $\mathbf{R}_{\mathrm{C}}$}

\section{$2.1 \quad$ Overview}

Using the data for a side-grooved CTOD sample of steel, the specific work of fracture may be determined over a portion of the load-displacement X-u plot shown in Figure 1. If the applied strain energy in the crack tip process zone exceeds $\mathrm{R}$ at any point then the crack will propagate. Stable crack growth typically occurs for ductile steels throughout the testing indicated by a rising $\mathrm{R}$ curve. If the applied strain energy is subsequently reduced then the crack will stop growing. However a limiting upper bound or critical value $\mathrm{R}_{\mathrm{c}}$ can eventually be reached after which the crack will continue propagating or running after removal of the applied loading.

Taking the load, X, near the limiting value and the corresponding load line displacement the work of fracture in the crack tip process zone at the load may be determined by comparison with an adjacent load and displacement for an increased crack length as shown in Figure 2. The fatigue crack length is measured in conjunction with the net width at the side-grooved crack front to allow a change in crack area to be assessed.

From the Direct Current Potential Drop (DCPD) output the crack length at each load can be determined using a pre-calibrated crack length curve. The elastic component of displacement may then be determined at each load to assess the compliance of the specimen at each crack length. From BS 7446-1:1997 Eq. 11 the elastic displacement of a 3 point bend CTOD specimen with side-grooves is :

$\mathrm{u}_{\mathrm{el}}=\frac{\mathrm{F}\left(1-\mathrm{v}^{2}\right)}{\mathrm{EB}_{\text {eff }}}\left(\frac{\mathrm{S}}{\mathrm{W}-\mathrm{a}}\right)^{2}\left\{1.193-1.980\left(\frac{\mathrm{a}}{\mathrm{W}}\right)+4.478\left(\frac{\mathrm{a}}{\mathrm{W}}\right)^{2}-4.443\left(\frac{\mathrm{a}}{\mathrm{W}}\right)^{3}+1.739\left(\frac{\mathrm{a}}{\mathrm{W}}\right)^{4}\right\}$

and the effective width of the specimen is given as

$\mathrm{B}_{\mathrm{eff}}=\mathrm{B}-\left(\frac{\left(\mathrm{B}-\mathrm{B}_{\mathrm{N}}\right)^{2}}{\mathrm{~B}}\right)$

Therefore plastic displacement after unloading from each load point is the measured displacement minus the elastic component. The total work done in the specimen as the crack advances is the area within the curve LMNP of Figure 1.

The specific work of fracture in the crack process zone as the crack advances is the area within the curve LQP of Figure 2. If for elastic brittle fracture to occur the remote plastic flow would be zero and the radial elastic compliance lines would converge to the same point. So the approach taken here is to say that there is a component of crack tip fracture that occurs whether in a field of remote plastic flow or not. The magnitude of this component can be identified by converging the change in elastic compliance back to the point of origin of the elastic compliance curve prior to the change of crack length being investigated. To make the convergence however the new elastic compliance curve must be displaced back by the amount of the net plastic displacement developed in increasing the crack length. 
The work done in plastic flow in side-grooved CTOD specimens of 300Plus steel conforming to G300 AS3679 constructional steel, tested in this study, can be as much as 33 times greater than the specific work of fracture. This shows how significant the remote plastic flow is on the energy balance in these samples and underlines the importance of isolating the remote plastic flow components from any assessment of fracture toughness gained from small sample testing. Care is also required when applying small scale test results to large scale situations.

A comparison of the calculated value of $\mathrm{R}_{\mathrm{c}}=37.3 \mathrm{~kJ} / \mathrm{m}^{2}$ obtained from the CTOD specimen in this study shown in Figure 1 and Figure 2 with those published by Atkins and Mai [2] indicates that this is within the range for carbon steels. A medium carbon steel is listed with $\mathrm{R}=14 \mathrm{~kJ} / \mathrm{m}^{2}$, a high strength alloy having $\mathrm{R}=45 \mathrm{~kJ} / \mathrm{m}^{2}$ listed.

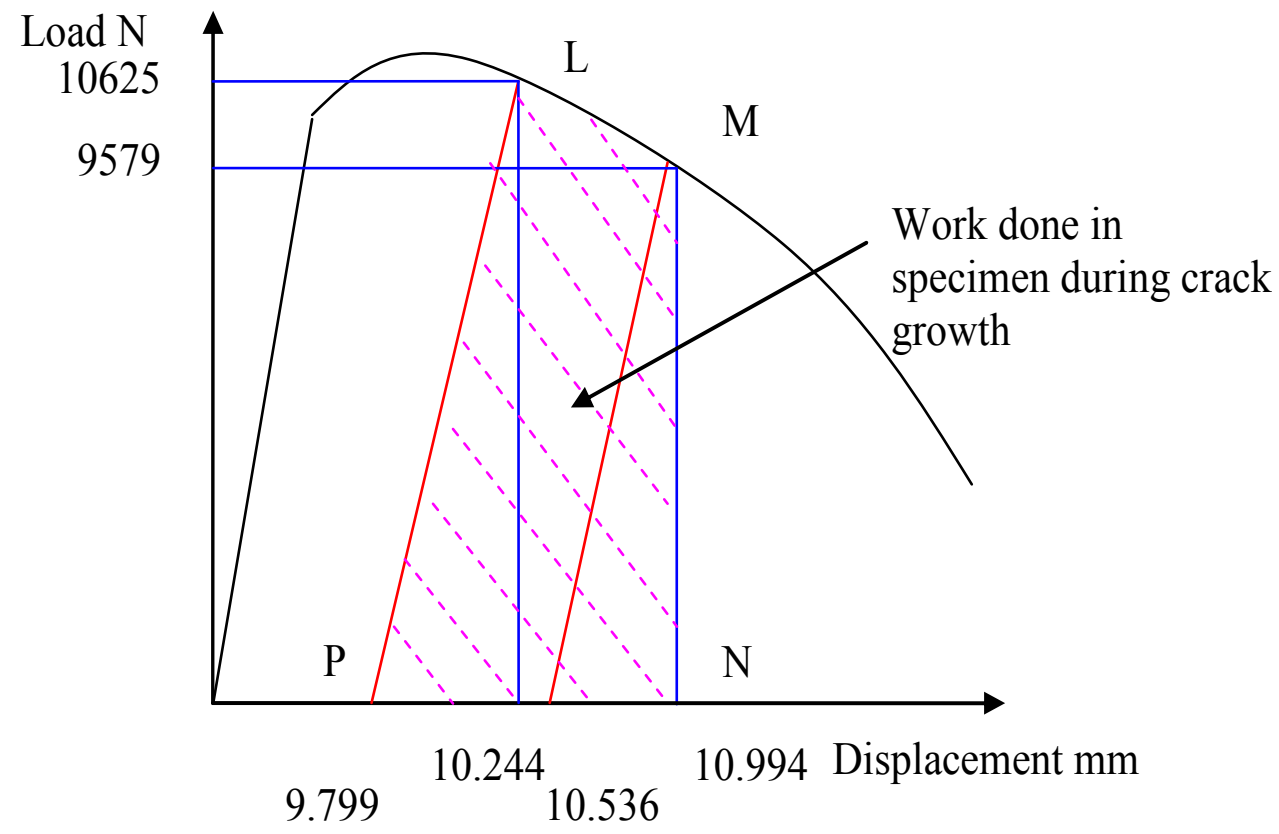

Figure 1. Total Work Done During Crack Growth in the Presence of Remote Plastic Flow

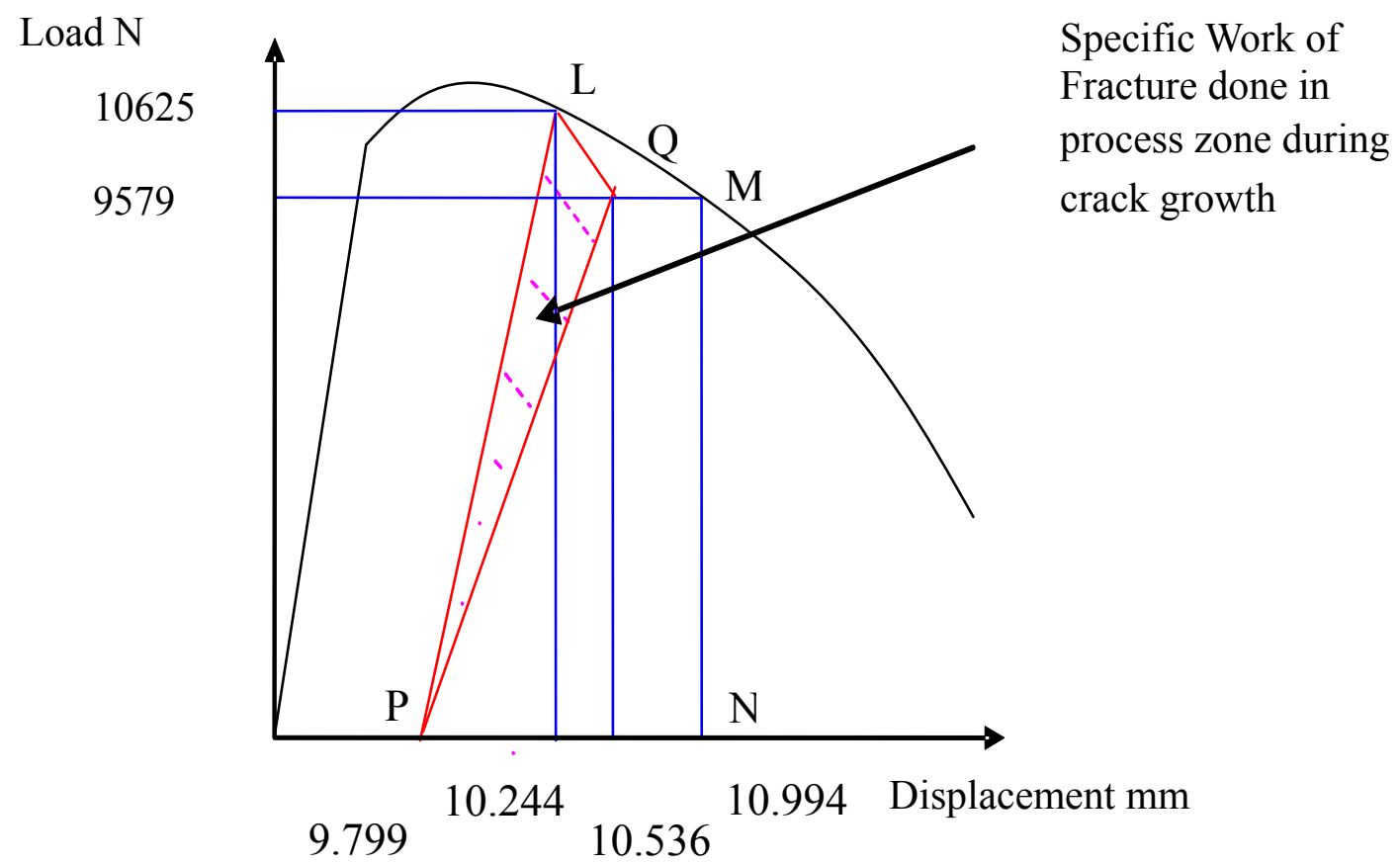

Figure 2. Specific Work of Fracture in Process Zone 
The method used for determining $\mathrm{R}_{\mathrm{c}}$ can be applied to data collected from CTOD testing when DCPD measurement of crack area growth has been used. This was done in tests undertaken as part of this study. Incremental specific work of fracture calculations can be made for every recorded increment of crack area growth. Curves developed in this way are shown for each pre-strained steel, combined into a single summary graph in Figure 3.

\subsection{Effect of Strain Hardening and Aging on the R Curve}

The plots of $\mathrm{R}$ versus crack area reveal a number of interesting features of toughness variation with strain hardening and aging. The first observation is that no matter the level of strain hardening all the samples of a particular steel eventually develop $\mathrm{R}$ curves that approach a reasonably consistent upper bound value of $R_{c}$. The main effect of strain hardening appears to be that of 'tightening' the $R$ curve, so that less crack development is required to develop the critical $\mathrm{R}_{\mathrm{c}}$ value. This is highlighted in the stylised representation of specific work of fracture versus crack area shown in Figure 5. The biggest change in the $\mathrm{R}$ curves is seen between that of the as-received steel and the $4.9 \%$ pre-strained steel. A smaller sharpening of the curve occurs between the $4.9 \%$ and $9.8 \%$ pre-strained steels. A plateau value of $38 \mathrm{~kJ} / \mathrm{m}^{2}$ is indicated by all the samples if they avoid development of brittle fracture. The plateau value provides a useful upper bound for constructional steel assessment purposes.

The running fracture behaviour of the $9.8 \%$ and $17.7 \%$ pre-strained specimens at $10{ }^{\circ} \mathrm{C}$ and $20{ }^{\circ} \mathrm{C}$ indicates that the additional effect of strain aging and temperature has elevated the initiation point above the $R_{c}$ value so that any crack development will result in fast running fracture.

Specific Work of Fracture R vs Normalised Crack Length CTOD 0\% Pre-strain 300+ \& M

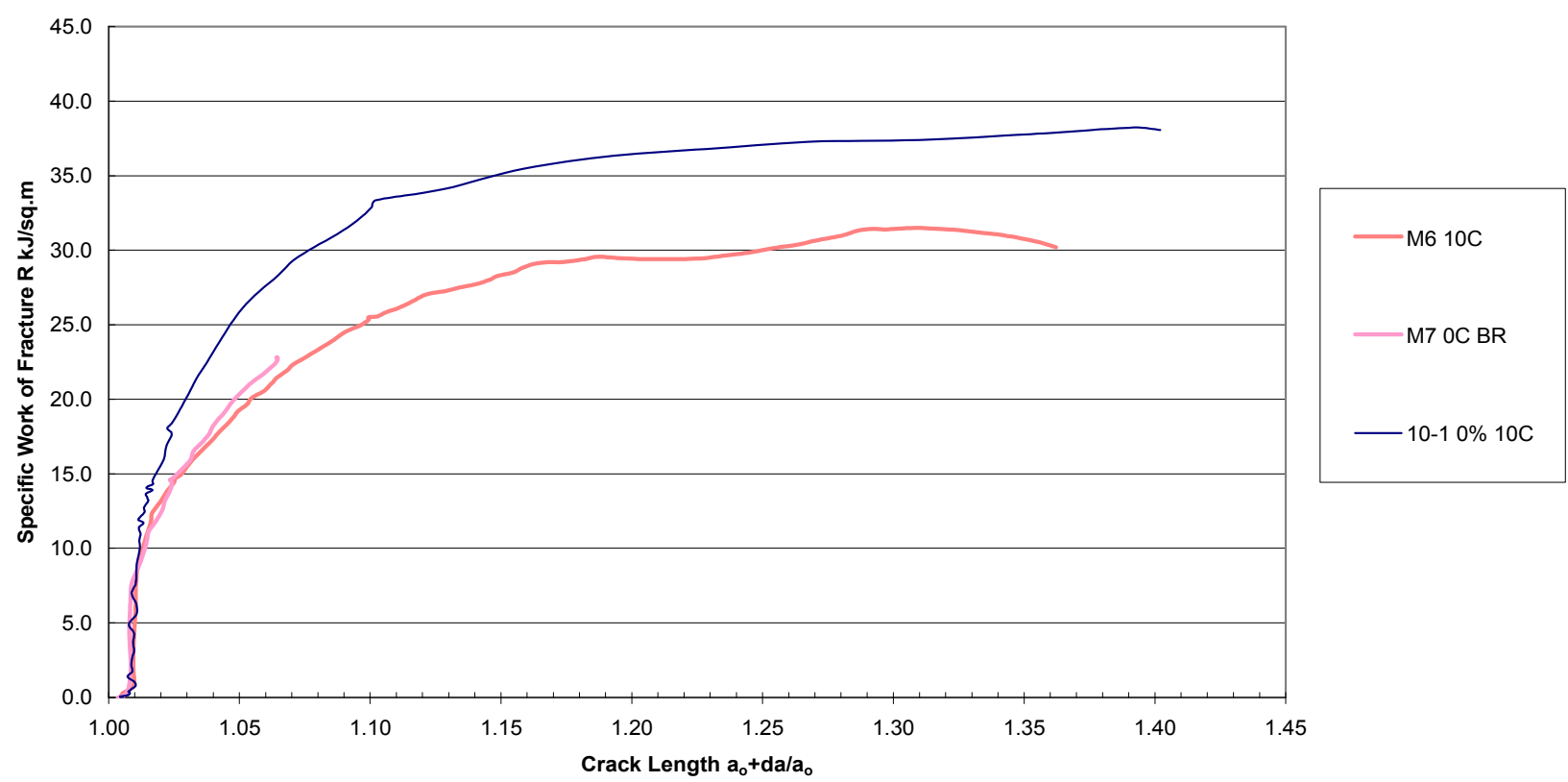

Figure 3. Specific Work of Fracture R vs Crack Length for Unknown M Steel Compared to 300+ As-Received 


\subsection{Summary R Curves of Another Steel}

CTOD test results M6 and M7 were for a steel with similar yield strength to the 300Plus steel, but not traceable to a particular grade or manufacturer. A plateau value of $30 \mathrm{~kJ} / \mathrm{m}^{2}$ is indicated by $\mathrm{M} 6$, though M7 failed with running fracture at $22 \mathrm{~kJ} / \mathrm{m}^{2}$. When compared to the 300 Plus steel there is clearly a significant drop in toughness (Figure 4). However the constructional steel characteristic of a soft curving $\mathrm{R}$ similar to that of the as-received 300Plus steel is still evident.

Specific Work of Fracture R vs Normalised Crack Length $0 \%-17.7 \%$ Pre-strain

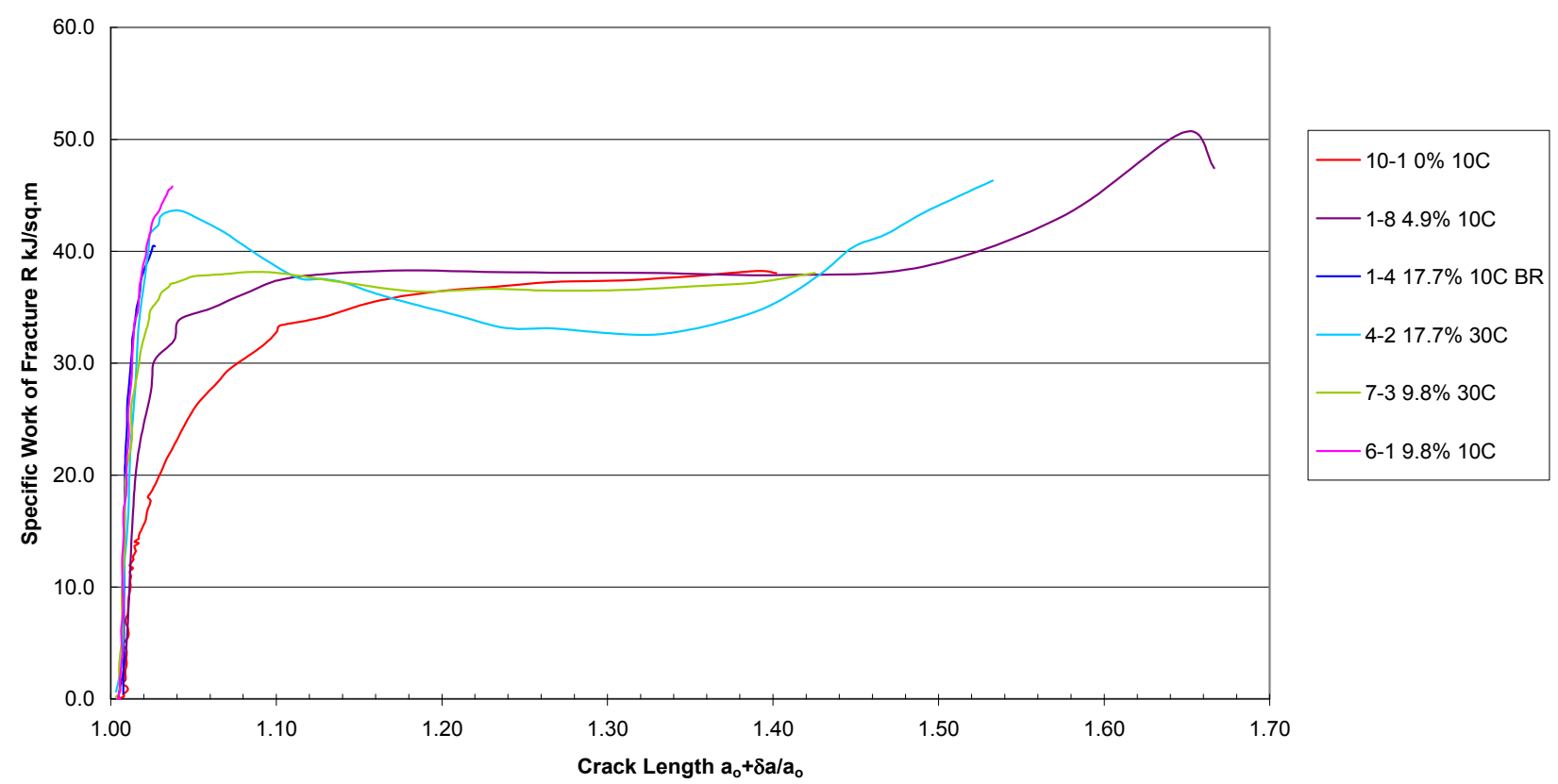

Figure 4. Specific Work of Fracture R vs Crack Length Summary for 300+ Steel

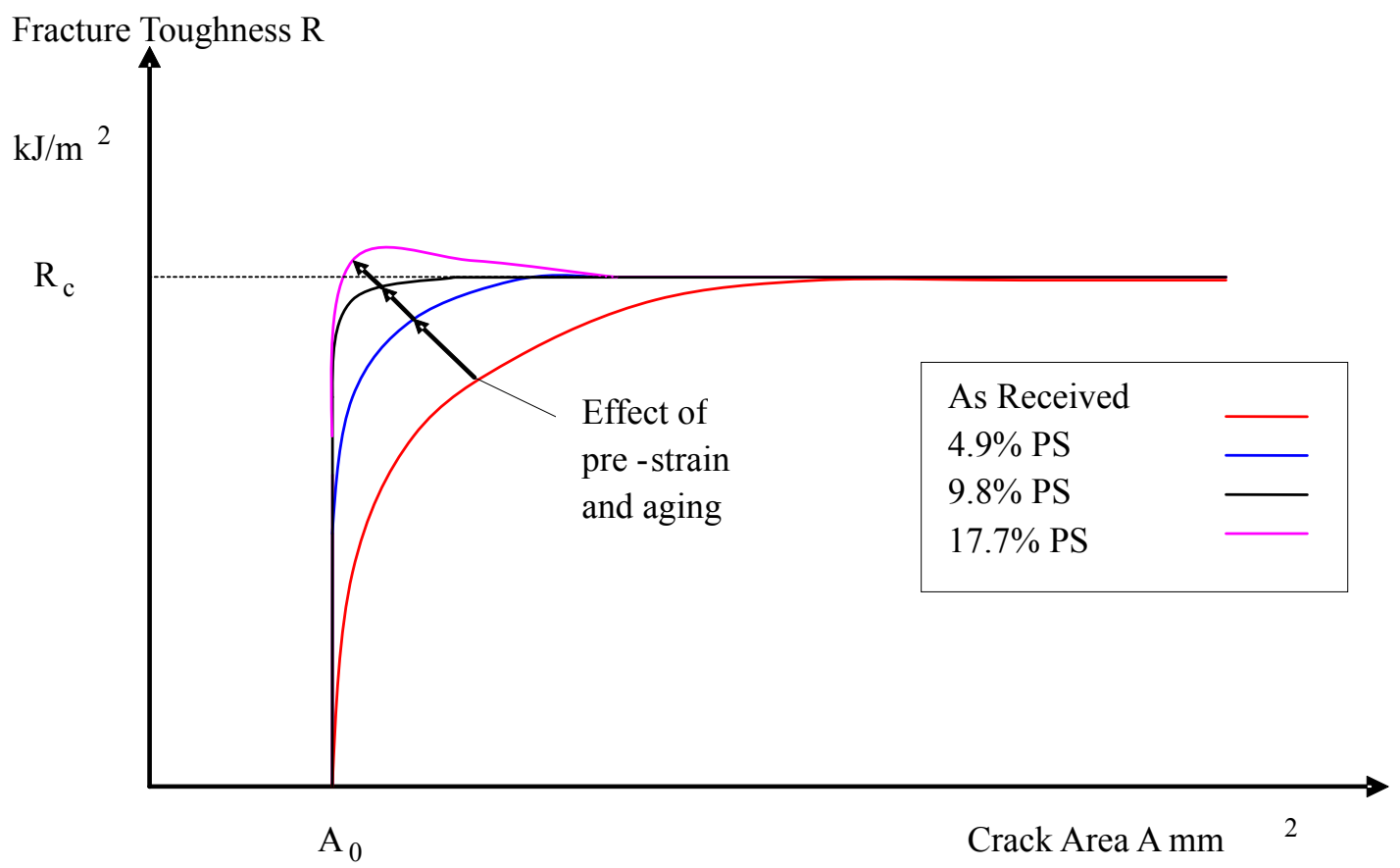

Figure 5. Stylised Specific Work of Fracture vs Crack Area, Showing the Effect of Pre-Strain and Aging 


\subsection{Equivalent $K_{r}$ Values}

An equivalent elastic stress intensity at fracture can be derived from the $R_{c}$ values of $38 \mathrm{~kJ} / \mathrm{m}^{2}$ for the 300 Plus steel and $30 \mathrm{~kJ} / \mathrm{m}^{2}$ for the $\mathrm{M}$ series steel, by considering plane strain conditions to have been present in the CTOD samples as evidenced by the square fracture behaviour.

$$
\mathrm{K}_{\mathrm{Rc}}^{2}=\mathrm{E}^{*} \mathrm{R}_{\mathrm{c}}
$$

$$
\mathrm{K}_{\mathrm{Rc}}=\sqrt{\frac{\mathrm{ER}_{\mathrm{c}}}{1-v^{2}}}=\sqrt{\frac{210 \times 10^{3} \times 38 \times 10^{-3}}{1-0.3^{2}}}=93.6 \mathrm{MPa} \sqrt{\mathrm{m}}
$$

for 300Plus steel samples

$$
\mathrm{K}_{\mathrm{Rc}}=\sqrt{\frac{210 \times 10^{3} \times 30 \times 10^{-3}}{1-0.3^{2}}}=83.2 \mathrm{MPa} \sqrt{\mathrm{m}}
$$

for the unknown M series steel.

These values are well within the range for $\mathrm{K}_{\mathrm{Ic}}$ values identified for constructional steels, adding to the confidence that this approach is valid. Such a value is particularly useful in allowing an upper bound approach to be applied to normal structural analyses. The peak strain hardened stress in a section may be used to identify whether the peak equivalent elastic stress intensity will be exceeded during the course of a load cycle irrespective of whether plastic flow is present or not.

\section{SUMMARY OF FINDINGS WITH RESPECT TO SPECIFIC WORK OF FRACTURE DERIVED R CURVES}

Realistic values of fracture toughness have been derived using the specific work of fracture approach. These correspond well to published values of $\mathrm{R}$ and $\mathrm{K}_{\mathrm{Ic}}$ found for constructional steels. The method is able to distinguish between one steel and another as evidenced by the differing values for the 300Plus steel and M series steels tested.

Where the rate of change of the applied crack tip strain energy $G$ is greater than the change in the crack growth resistance $\mathrm{R}$, unstable crack propagation will occur. The effect of pre-strain is to sharpen the curvature of the $\mathrm{R}$ curve such that less crack growth is required before a critical $\mathrm{R}_{\mathrm{c}}$ value is reached at which the crack will propagate. When $R_{c}$ is reached and significant remote plastic flow is available then stable crack propagation will result as the remote plastic flow will absorb the strain energy released by crack propagation. When $R_{c}$ is reached and the energy balance in the specimen is dominated by elastic strain energy then fast unstable running fracture is expected to occur.

With cyclic loading the steel is being put through elastic and plastic strain hardening cycles so the energy balance within the steel at a particular stress state is dependent on its strain history. For example when reloading up to a strain hardened stress after an unloading phase, unstable running fracture will result if the critical $R_{c}$ value is reached and no plastic flow is available to dissipate the release of strain energy upon crack propagation. 
The effect of strain aging may be mainly limited to steel that has been significantly strain hardened such that the strain aged ultimate tensile strength is elevated above the as-received ultimate tensile stress. The effect is that it will be almost impossible for the steel to develop remote plastic flow should $\mathrm{R}_{\mathrm{c}}$ be reached as any plastic deformation would have to be localised into necking which has a reduced energy state compared to strain hardening plastic flow.

It is therefore productive to investigate the combined effect of deformation behaviour with strain hardened material property curves and $\mathrm{R}$ on specimens with varying crack areas. The deformation plasticity effects are considered to be linked by the common energy balance requirement.

Geometrical size effects need to be considered when applying the $R_{c}$ values derived from small scale specimens to large scale structures as while the material properties will be the same if the same material is used, the energy balance may be significantly different. Potentially, more elastic strain energy may be available relative to remote plastic deformation in a larger specimen than in a smaller one. Such effects may be identified by elasto-plastic modelling in appropriate FEA software.

\section{EXAMPLE ASSESSMENT OF MONOTONIC FRACTURE LIMIT STATES IN A STEEL BAR}

\subsection{Overview}

In order to investigate the combined effects of deformation plasticity history and specific work of fracture it is necessary to be able to determine what particular deformation will occur under a load, including the plastic and elastic deformation components. The elastic component can be determined by modelling the specimen in FEA software with elastic properties and varying crack lengths. The plastic deformation component may similarly be modelled but using true plastic stress- log strain data for each strain hardened state of the steel.

\subsection{Determination of Bar Elastic Compliance Function}

A $50 \mathrm{~mm}$ deep x $40 \mathrm{~mm}$ wide rectangular bar simply supported with a span of $600 \mathrm{~mm}$ and a single point load was modelled in ABAQUS (Figure 6). The bar is similar to one reported by Kuwamura and Takagi [3], with a $0.5 \mathrm{~mm}$ deep 30 degree notch cut into the top and bottom faces. In this case however no deepening in the section occurs at mid-span apart from variation in the crack depth on the tension face. This was done to simplify the FEA modelling (Figure 7). The bar is sized so that shear stresses are small and won't cause significant interaction effects with the flexural stresses.

Crack lengths of $0.5,2.0,3.0,5.0,8.0$ and $10.0 \mathrm{~mm}$ were modelled on the tension face to determine the change in elastic compliance of the bar as the crack length increased. The bar was subjected to a mid-span displacement of $1.0 \mathrm{~mm}$ for each crack length and a curve fitted to the data to determine an equation for elastic compliance as plotted in Figure 8.

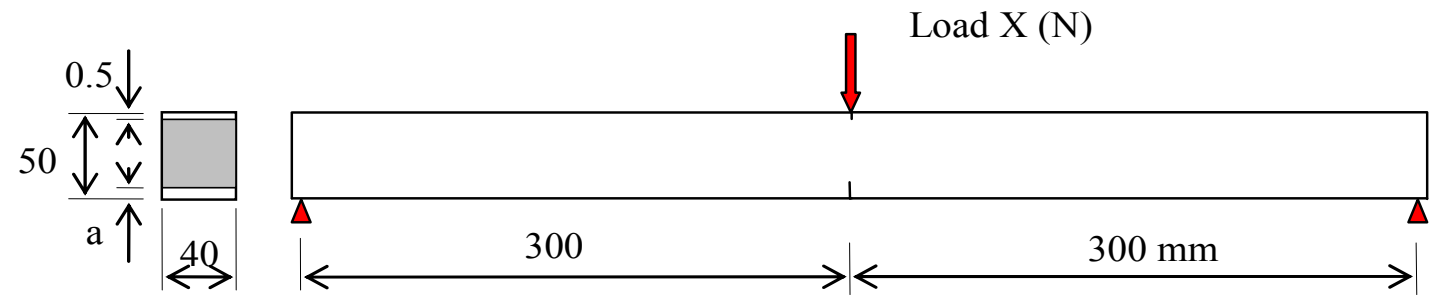

Figure 6. 50 x $40 \mathrm{~mm}$ Cracked Steel Bar Used in FEA Model 


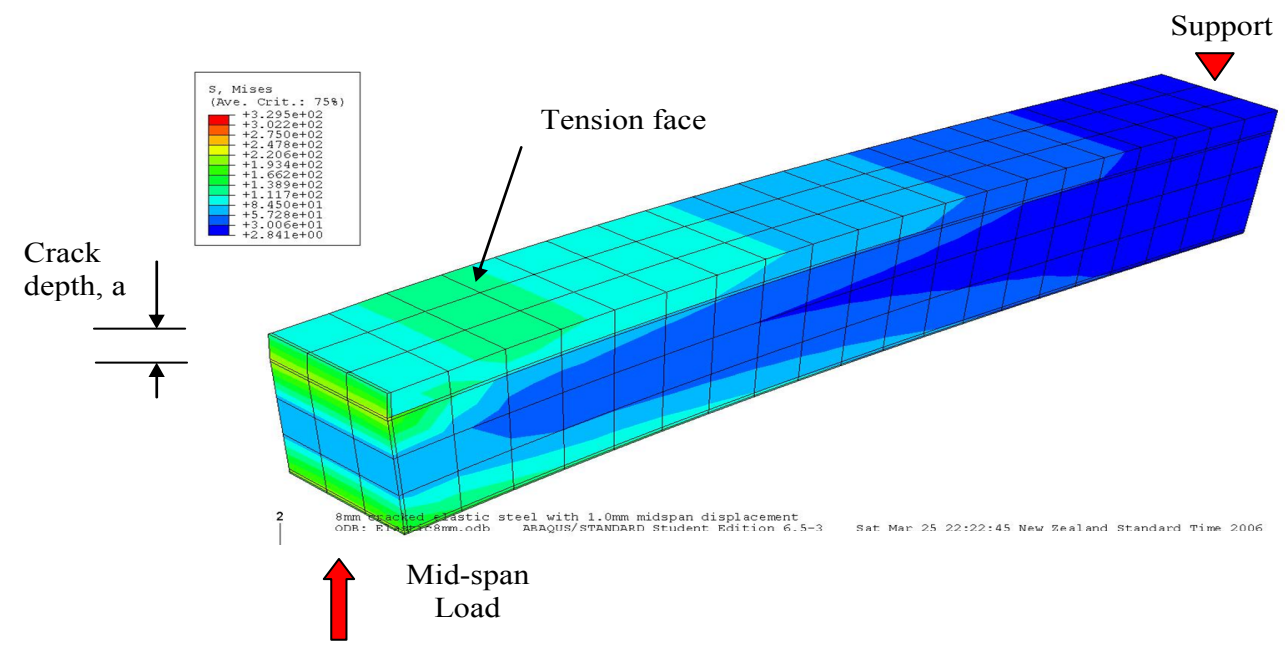

Figure 7. Elastically Deformed FEA Model of Half Span of 50 x 40 mm Bar (Loaded Upwards)

Elastic Midspan Load vs Crack Length at 1.0mm Displacement

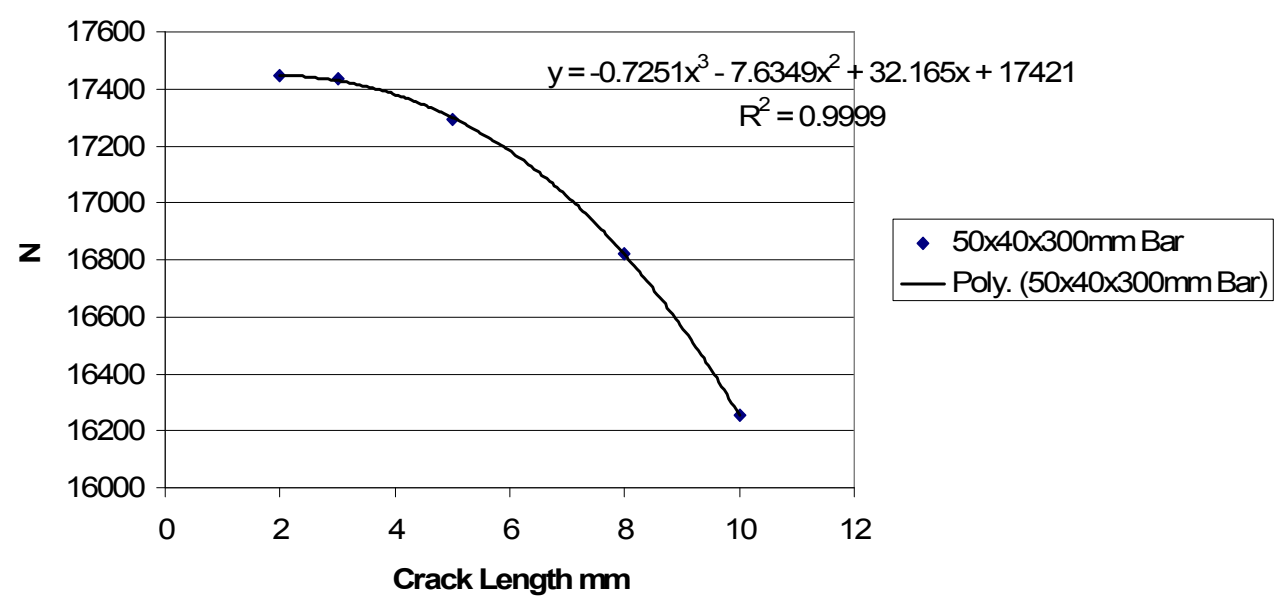

Figure 8. Elastic Compliance Function of Cracked 50 x 40 mm Bar From FEA

\subsection{Calculation of Critical Crack Propagation Load}

For each crack length case the mid-span load at which unstable running crack propagation would be predicted by $R_{c}$ was calculated and compared to the plastic hinge load for the specimen with the range of strain hardened tensile stress strain properties derived from pre-straining tests by the authors [1]. A published applied crack tip strain energy, G, expression in terms of $\mathrm{R}$ for a notched bar published by Atkins and Mai [2] is used to determine cracking moment $\mathrm{M}_{\mathrm{Rc}}$. For a rectangular bar in flexure this is

$\mathrm{E}^{*} \mathrm{R}=\frac{36 \mathrm{M}_{\mathrm{Rc}}{ }^{2} \mathrm{a}}{\mathrm{t}^{2} \mathrm{~W}^{4}} \mathrm{Y}^{2}$

$\mathrm{Y}=1.992-2.468\left(\frac{\mathrm{a}}{\mathrm{W}}\right)+12.97\left(\frac{\mathrm{a}}{\mathrm{W}}\right)^{2}-23.17\left(\frac{\mathrm{a}}{\mathrm{W}}\right)^{3}+24.80\left(\frac{\mathrm{a}}{\mathrm{W}}\right)^{4}$ 


$$
\begin{aligned}
& \mathrm{a}=\text { Crack depth }(\mathrm{m}) \quad \mathrm{W}=\text { Bar depth } \quad \mathrm{t}=\text { Bar thickness } \\
& \mathrm{L}=\text { Bar span } \quad \mathrm{M}_{\mathrm{Rc}}=\text { Bending moment at mid }- \text { span }(\mathrm{kNm})
\end{aligned}
$$

This equation can be re-written in terms of the critical cracking moment $\mathrm{M}_{\mathrm{Rc}}$

$$
\begin{aligned}
& M_{R c}=\sqrt{\frac{E^{*} \mathrm{Rt}^{2} W^{4}}{36 a Y^{2}}}=\frac{X_{R c} L}{4} \\
& E^{*}=\frac{E}{1-v^{2}} \quad \text { plane strain }
\end{aligned}
$$

For an $8 \mathrm{~mm}$ crack in the bar, with $\mathrm{R}=38 \mathrm{~kJ} / \mathrm{m}^{2}$

$$
\begin{aligned}
& \mathrm{Y}=1.992-2.468\left(\frac{8}{50}\right)+12.97\left(\frac{8}{50}\right)^{2}-23.17\left(\frac{8}{50}\right)^{3}+24.80\left(\frac{8}{50}\right)^{4}=1.851 \\
& \mathrm{M}_{\mathrm{Rc}}=\sqrt{\frac{210000 \times 38000 \times 0.04^{2} \times 0.05^{4}}{\left(1-0.3^{2}\right) \times 36 \times 0.008 \times 1.851^{2}}}=9.427 \mathrm{kNm} \\
& \mathrm{X}_{\mathrm{Rc}}=\frac{4 \mathrm{M}_{\mathrm{Rc}}}{\mathrm{L}}=\frac{4 \times 9.427}{0.60}=62.85 \mathrm{kN}
\end{aligned}
$$

\subsection{Upper Bound Plastic Hinge Load}

Upper bound mid-span loads for a notched bar (Figure 9) may be calculated for plastic hinge development using classical virtual work approaches for a rectangular bar by Knott [4]. A plastic hinge with a maximum included angle of $66^{\circ} 50^{\prime}$ gives

$$
\begin{aligned}
& \mathrm{M}_{\mathrm{pl}}=\tau_{\mathrm{y}} \mathrm{t} \frac{(\mathrm{W}-\mathrm{a})^{2}}{2} \operatorname{cosec} \mathrm{ec}^{2} \alpha \cdot \alpha=0.345 \sigma_{\mathrm{y}} \mathrm{t}(\mathrm{W}-\mathrm{a})^{2} \\
& \sigma_{\mathrm{y}}=2 \tau_{\mathrm{y}}
\end{aligned}
$$

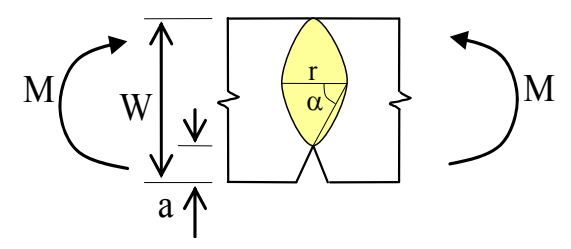

Figure 9. Plastic Hinge Zone in Notched Bar

This would be bounded by the gross unnotched section plastic moment limit from beam theory of

$\mathrm{M}_{\mathrm{pl}}=0.25 \sigma_{\mathrm{y}} \mathrm{tW}$

If the cracking moment $M_{R c}$ is reached before the section reaches $M_{p l}$ then running fracture will occur before the attainment of the reference value of monotonic displacement ductility $\mu=1$. To allow for strain hardening after significant rotation, the yield stress is substituted for the flow stress, the average of the yield and ultimate tensile stress of the material 
$\sigma_{\mathrm{fl}}=\frac{\sigma_{\mathrm{y}}+\sigma_{\mathrm{u}}}{2}$

So for the bar with an $8 \mathrm{~mm}$ crack in as-received 300Plus steel the upper bound plastic hinge loads at yield for a notched and full section are

$$
\begin{aligned}
& M_{\text {pl.notch }}=0.345 \times 307 \times 40 \times(50-8)^{2} \times 10^{-6}=7.473 \mathrm{kNm} \\
& M_{\text {pl.gross }}=0.25 \times 307 \times 40 \times 50^{2} \times 10^{-6}=7.675 \mathrm{kNm} \\
& M_{\text {pl.hinge }}=7.473 \mathrm{kNm}
\end{aligned}
$$

For a crack depth of $8 \mathrm{~mm}$ the notched section hinge capacity governs hinge formation at 7.473 $\mathrm{kNm}$. This is less than $\mathrm{M}_{\mathrm{Rc}}=9.427 \mathrm{kNm}$, so running fracture won't occur before full development of the plastic hinge.

The maximum strain hardened or over-strength plastic hinge moment of the cracked section $\mathrm{M}_{\mathrm{os}}$ using the flow stress is

$$
\begin{aligned}
& \sigma_{\mathrm{fl}}=\frac{306+511}{2}=409 \mathrm{MPa} \\
& \text { is } \\
& M_{\text {os.hinge }}=0.345 \times 409 \times 40 \times(50-8)^{2} \times 10^{-6}=9.956 \quad \mathrm{kNm}
\end{aligned}
$$

This is greater than $\mathrm{M}_{\mathrm{Rc}}$, so for an $8 \mathrm{~mm}$ deep crack, fast running fracture is expected after significant development of plastic hinge rotation, but before achievement of the theoretical upper bound strain hardened plastic hinge moment. Results of calculations for cracking moment and plastic hinge limit states are plotted to develop the surfaces in Figure 10, Figure 11 and Figure 12.

\subsection{Plastic Hinge Formation and Cracking Limit State Surfaces}

The limit state surface of bending moment at which crack propagation occurs is shown in Figure 10. The surface showing the point at which plastic hinge development occurs is seen in Figure 11, and the upper bound over-strength plastic moment surface is shown in Figure 12. These considered together show that as the crack lengthens and strain hardening increases then cracking will occur before a plastic hinge can fully form in some cases. In other cases cracking will occur after the development of a plastic hinge but before development of the hinge strain hardened or over-strength capacity. In the final case no cracking will occur before development of the strain hardened moment capacity followed by stable necking and micro-void coalescence based fracture. Cleavage fracture modes with rapid running fracture have been observed by Kuwamura and Takagi [3] in this last condition after necking has initiated. However such a mode of fracture is not modelled by the method proposed for the reasons discussed in the following section.

In summary the intersection of the crack propagation surface with the plastic hinge and strain hardened surfaces determines which limit state governs for a particular pre-strain and crack length. 
Critical Cracking Moment vs Crack Length \& Steel Pre-strain \%

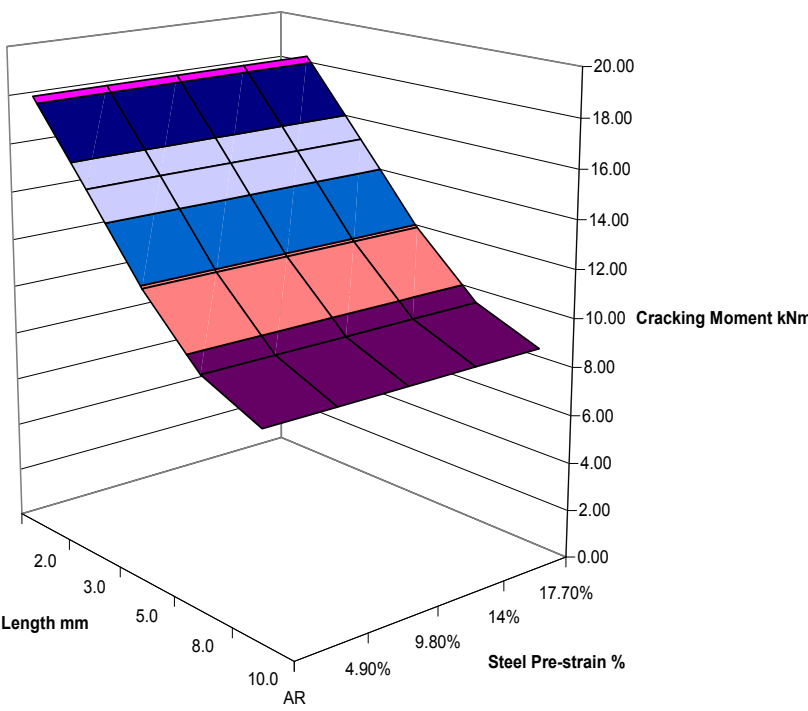

Figure 10. Cracking Moment Limit Surface

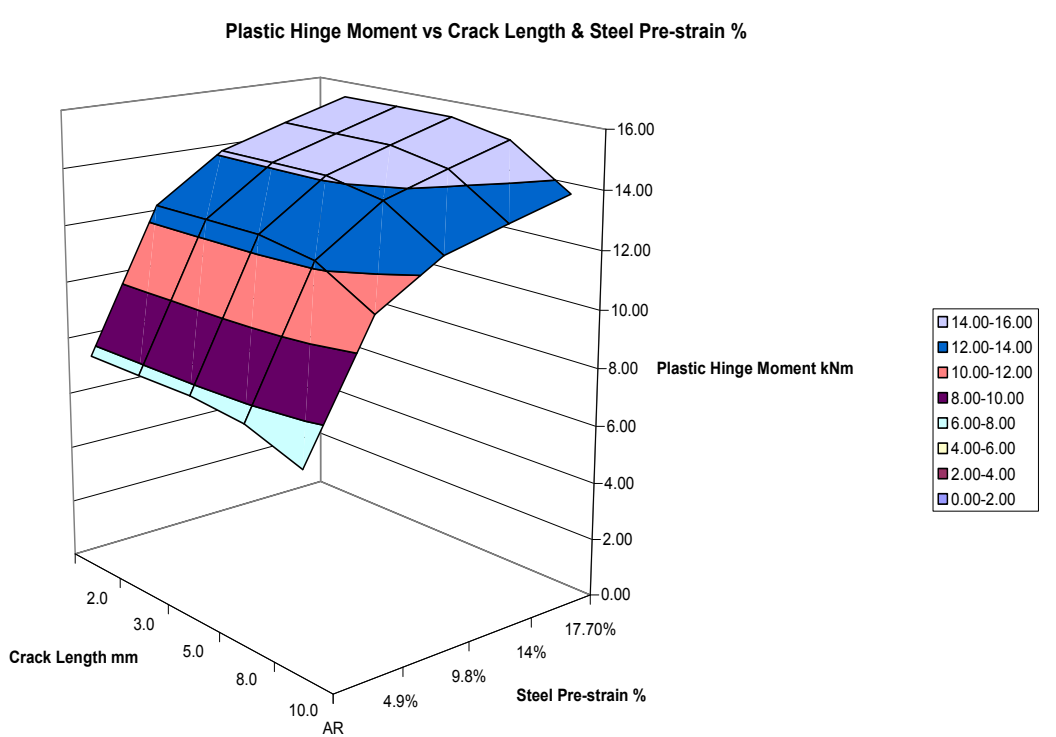

Figure 11. Plastic Hinge Development Limit Surface

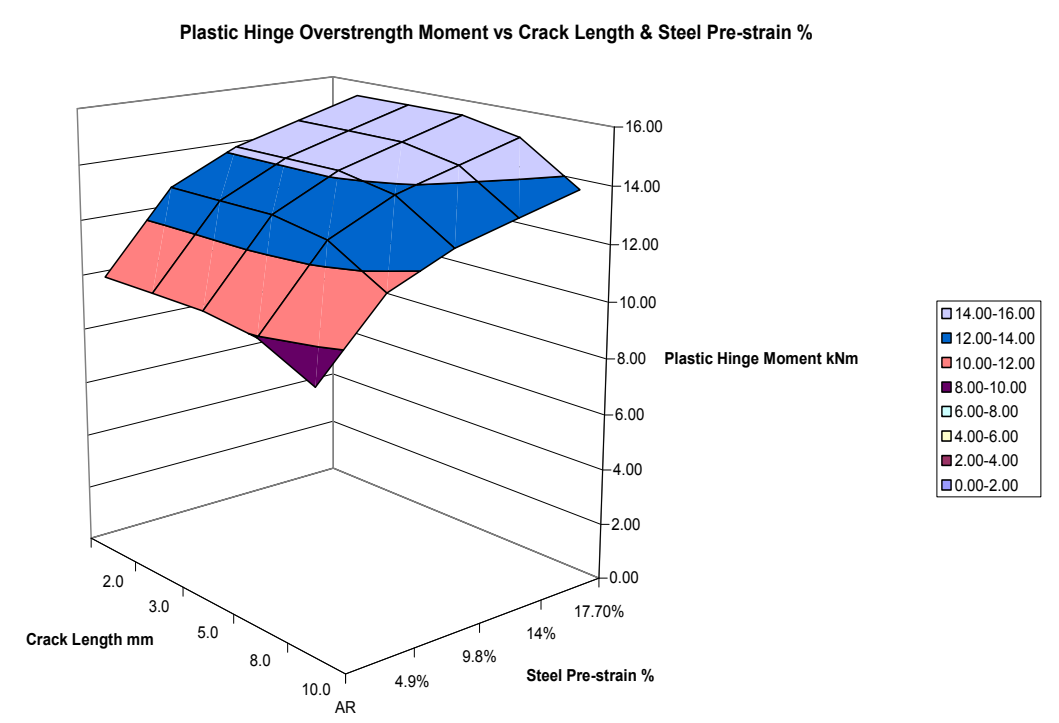

Figure 12. Over-Strength Moment Limit State Surface 


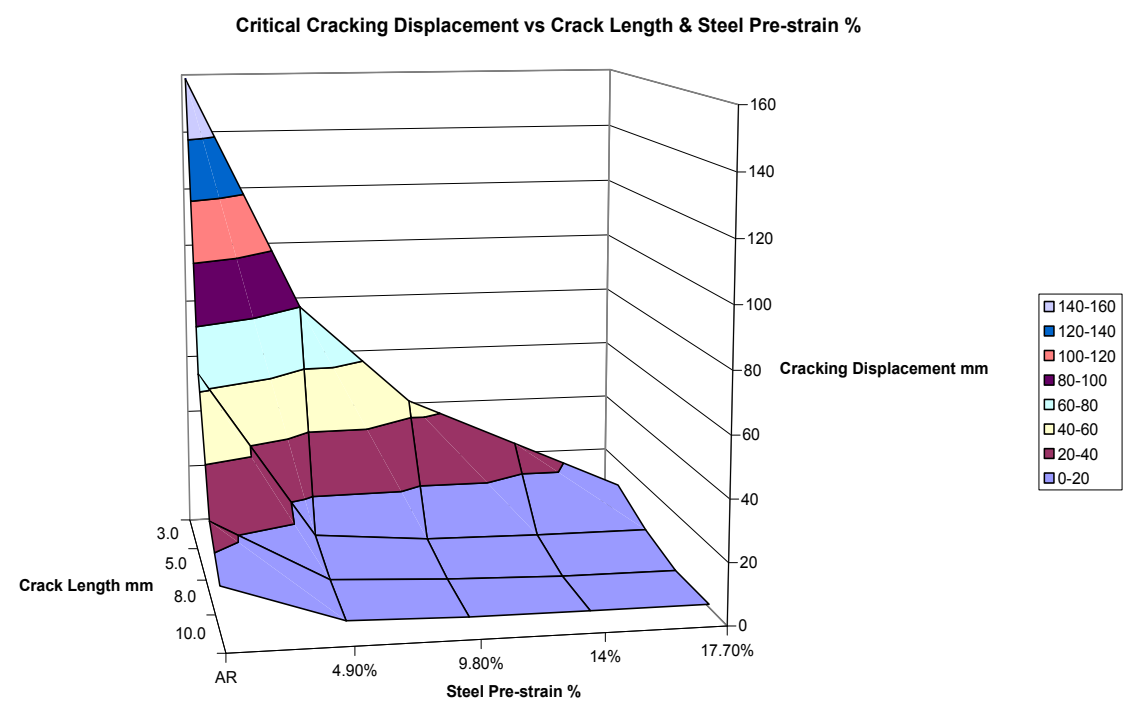

Figure 13. Displacement Limits for Pre-Strained Steel with Varying Crack Lengths

\subsection{Member Displacement at Cracking Load and Necking}

There will be a limit on how much rotation and therefore displacement can be sustained by the section before the other limiting condition of necking and ductile fracture occurs. Once necking occurs the cracking mechanism predicted by this method can not occur. This method assumes proportional elongation of the section, whereas once necking commences the elongation becomes localised and stable fracture involving micro-void coalescence is assumed to occur.

The point at which necking commences is not easy to determine even using Finite Element Analysis (FEA). A different set of modelling assumptions are needed to consider the effect of micro-void coalescence involving continuum mechanics. In that approach the steel is modelled using porous plasticity theory. This requires assumptions about initial micro-particle density and size. Only a "best judged" estimate of properties can be made using published data used in some studies done internationally. Consequently the properties need to be confirmed on the basis of actual testing to calibrate the FEA model.

This would give some indication of whether running fracture failure will occur after the initiation of necking. In this study the modelling has not been taken to that level and is not necessary for most structural engineering considerations of ductility and endurance. This is because the initiation of necking also coincides with peak tensile strength of the material and thereafter a rapid drop off in load carrying capacity of the member. However, having determined the cracking load, and if some upper bound approach is used to identify the necking limit state, it is necessary to determine what the mid-span displacement of the bar will be at that load if a measure of member displacement ductility is sought.

To achieve this, the displacement of the bar at the calculated critical cracking load may be determined from an elasto-plastic FEA analysis of the bar at a given crack length. The same FEA models used for the determination of elastic compliance are used but with the actual tensile properties of the steels. In this instance a strain hardened moment capacity limit is defined using the flow stress as an upper bound average stress in the plastic hinge with full development of hinge rotations. 
It is apparent from the critical displacement plot that the ability of the steel bar to sustain significant displacement before cracking reduces as both strain hardening and crack length increases. Once over $4.9 \%$ pre-strain and $5 \mathrm{~mm}$ crack length, the bar can sustain no more than around $8 \mathrm{~mm}$ mid-span displacement before crack propagation occurs, whereas in the as-received condition with the same crack length the bar could sustain up to $65 \mathrm{~mm}$ displacement. This result goes a significant way to explaining observed behaviour in structures subjected to seismic inelastic demands.

\section{EXAMPLE ASSESSMENT OF CYCLIC MEMBER DUCTILE ENDURANCE}

\subsection{Overview}

The same $50 \mathrm{~mm}$ deep x $40 \mathrm{~mm}$ wide rectangular bar, simply supported with a span of $600 \mathrm{~mm}$, used in the assessment of monotonic fracture limit states is used to assess cyclic fracture limit states. Some knowledge of what the strain hardened state of the steel will be at a particular step in the cyclic loading cycle is then needed to make some assessment of the likelihood of stable plastic flow or running fracture at any point in the loading regime.

\subsection{Cyclic Ductility Using Similitude Approach}

The ability to assess the monotonic total displacement at which crack propagation will occur, allows the cyclic ductility to be determined for a range of cyclic displacement amplitudes using the Kuwamura Takagi [3] similitude relationship.

The monotonic displacement ductility, $\mu_{\mathrm{p}}$, is the ratio of the plastic displacement, $\delta_{\mathrm{p}}$, in terms of the elastic displacement at development of the gross section plastic moment, $\delta_{\mathrm{y}}$,

$$
\mu_{\mathrm{p}}=\frac{\delta_{\mathrm{p}}}{\delta_{\mathrm{y}}}
$$

For the $50 \mathrm{~mm} \times 40 \mathrm{~mm}$ bar with a $5 \mathrm{~mm}$ crack, running fracture is not expected to govern for the as-received steel. However if the $4.9 \%$ pre-strained steel was used the development of running fracture in the bar is predicted to occur at a lower load. The bar's monotonic displacement ductility, which is the plastic displacement at monotonic crack propagation or fracture over the elastic displacement at the development of plastic section capacity, may therefore be calculated for that pre-strained state.

\subsection{Monotonic Brittle Fracture Curves}

Monotonic brittle fracture curves may be calculated using this approach by determining the plastic displacement ratio at fracture under monotonic load

$$
\eta_{\mathrm{pM}}=\frac{\delta_{\mathrm{pM}}}{\delta_{\mathrm{y}}}
$$

for each of the crack lengths for each pre-strained steel state. The results of these calculations are plotted in Figure 14. 


\subsection{Constant Amplitude Cyclic Brittle Fracture Ductility to NZS 1170.5}

The similitude relationship allows the monotonic ductility ratings of the cracked steel beam in each pre-strain condition to be related to the NZS 1170.5 [5] cyclic ductility rating system. In the NZS 1170.5 context ductility is defined as,

$\mu=\frac{\delta_{\max }}{\delta_{y}}=\frac{\delta_{y}+\delta_{p}}{\delta_{y}}=1+\mu_{p}$

This is the total displacement ductility of the system being considered, not just the plastic displacement ductility used in the Japanese case. Under the NZS 1170.5 regime the specimen need only develop three cycles of displacement at a given constant displacement ductility without losing more than $20 \%$ of its strength. The New Zealand ductility requirement is one of the least severe requirements internationally as no development of damage needs to be accounted for in cycles preceding the ductility classification cycles.

For example the number of complete cycles that the as-received steel bar with a $2.0 \mathrm{~mm}$ crack at a ductility demand of $\mu=10$ will achieve is calculated as follows:

The monotonic plastic displacement ratio, $\eta_{\mathrm{pM}}=192$.

For $\frac{\eta_{\mathrm{pM}}}{\mu_{\mathrm{p}}} \geq 2$ the number of quarter cycles of plastic displacement at $\mu_{\mathrm{p}}$ is $\mathrm{N}_{\mathrm{f}}=\frac{\eta_{\mathrm{pM}}}{\mu_{\mathrm{p}}}\left(\frac{\eta_{\mathrm{pM}}}{\mu_{\mathrm{p}}}-1\right)^{2 / 3}$

Therefore the expected number of complete cycles $n$, is

$\mathrm{n}=\frac{\mathrm{N}_{\mathrm{f}}}{4}=\frac{192}{4 \times 10}\left(\frac{192}{10}-1\right)^{2 / 3}=\frac{159}{4}=39.8$

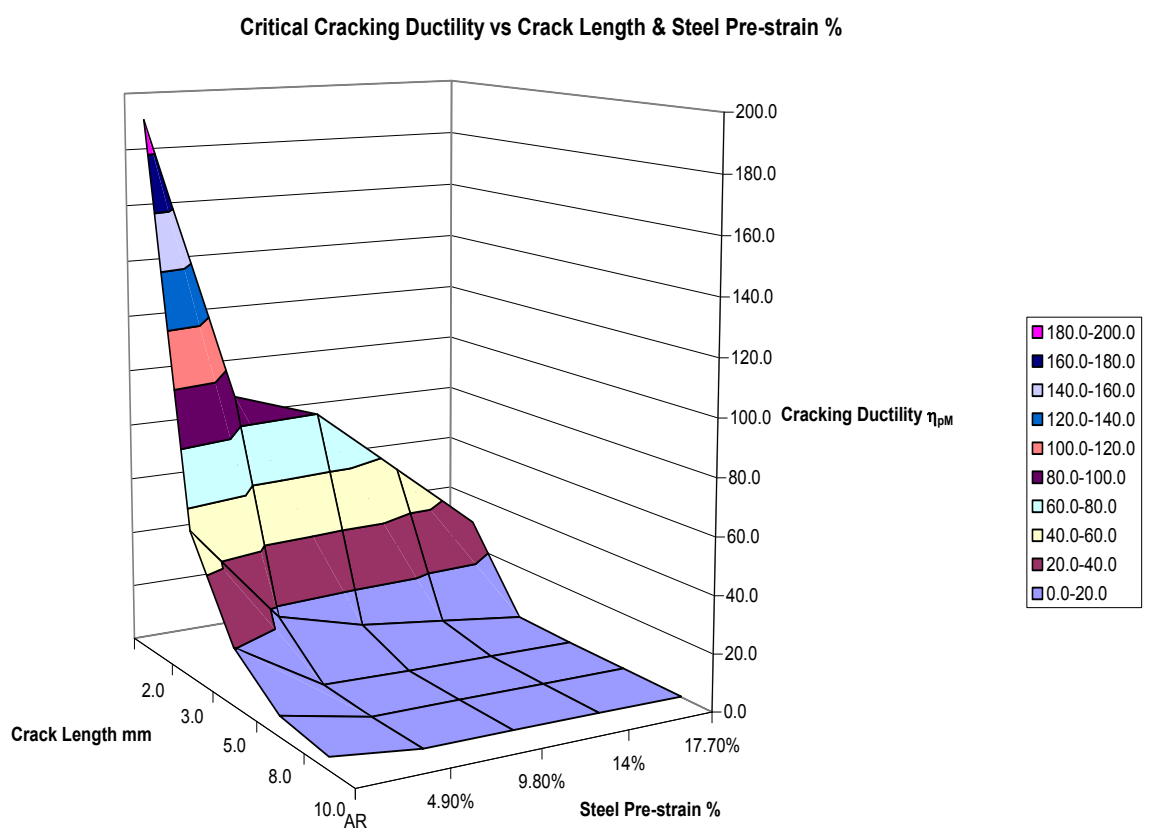

Figure 14. 50 x 40 x 600mm Bar:

Plot of Critical Cracking Ductility vs Crack Length and Steel Pre-Strain 


\subsection{Effect of $\mathbf{R}_{\mathrm{c}}$ on Cyclic Fracture Ductility and Endurance}

The effect of reduced critical specific work of fracture, $\mathrm{R}_{\mathrm{c}}$, values on the cyclic ductility of the bar can be determined using the method. When less than 12 quarter cycles or 3 full cycles are expected to be achieved by the specimen at that level of ductility demand it can not be categorised as able to achieve the particular ductility grading in accordance with NZS 1170.5.

The reduced cracking moment and related displacements lead to reduced monotonic ductility, $\eta_{\mathrm{pM}}$, and therefore reduced cyclic ductility. The effect of reducing the as-received steel toughness is significant. A comparative plot in Figure 15 of the two cyclic endurance and ductility curves $\mathrm{R}_{\mathrm{c}}=$ $38 \mathrm{~kJ} / \mathrm{m}^{2}$ and in Figure $16 \mathrm{R}_{\mathrm{c}}=30 \mathrm{~kJ} / \mathrm{m}^{2}$ shows a reduction in the cyclic endurance at all levels of ductility. The endurance of the tougher steel is three times that of the lower steel for the $2 \mathrm{~mm}$ cracked specimens; two times greater for the $3 \mathrm{~mm}$ cracked specimens; two and a quarter times greater for the $5 \mathrm{~mm}$ cracked specimens; and three times greater for the 8 and $10 \mathrm{~mm}$ cracked items. It is therefore clear that the specific work of fracture property of a steel, has a significant effect on the ductility and cyclic endurance of structural steel members.
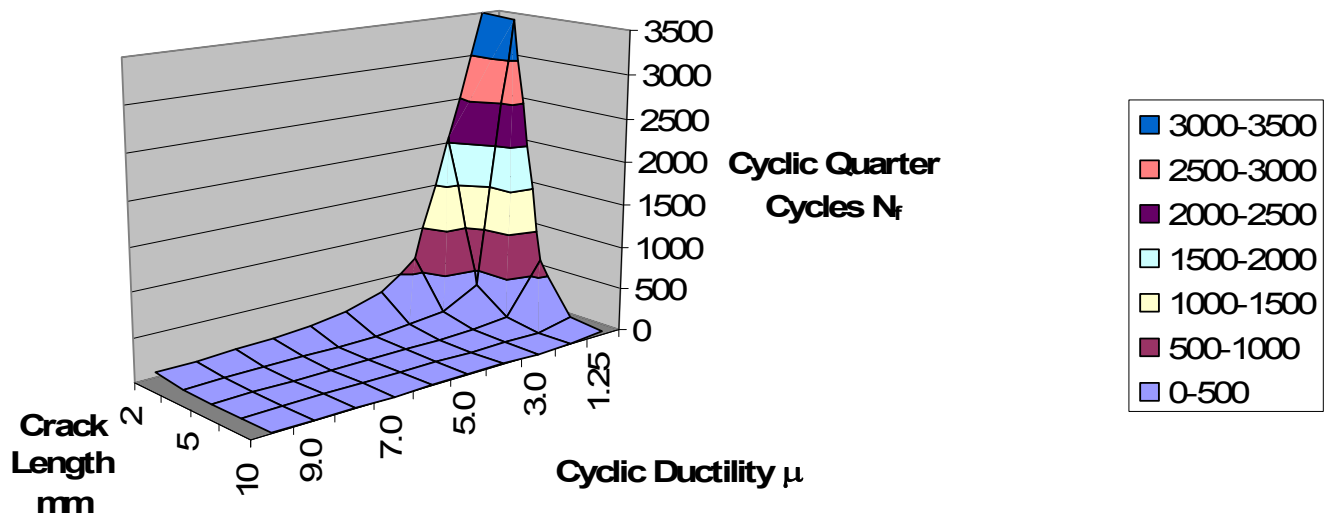

Figure 15. Cyclic Endurance and Ductility of As-Received $R_{c}=30 \mathrm{~kJ} / \mathrm{m}^{2}$ Steel
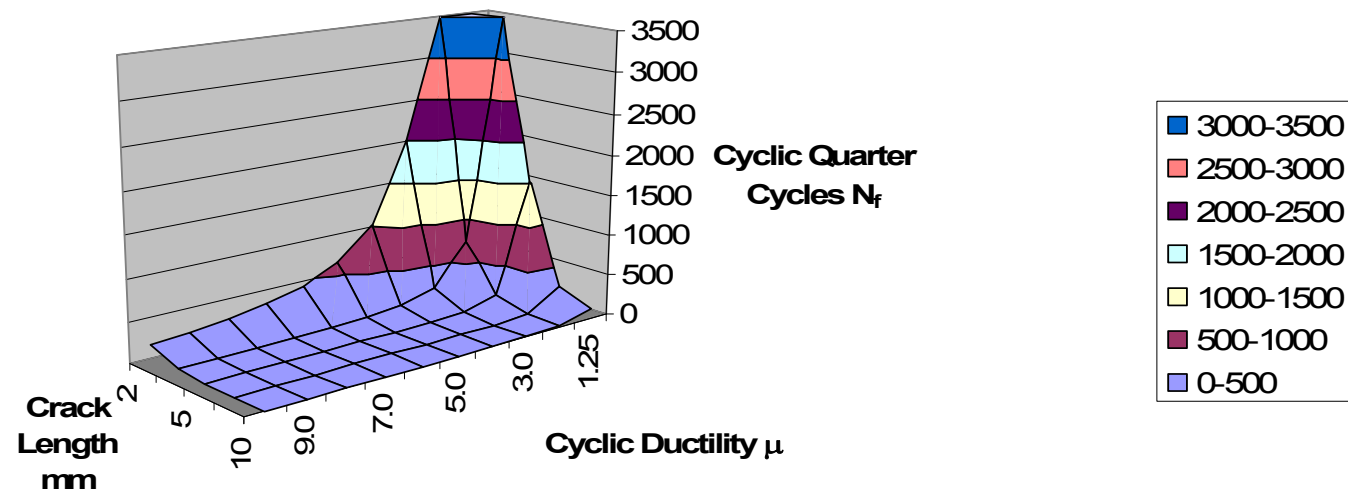

Figure 16. Cyclic Endurance and Ductility of As-Received $R_{c}=38 \mathrm{~kJ} / \mathrm{m}^{2}$ Steel 


\subsection{Application to Variable Amplitude Cyclic Loading}

The above analysis shows how constant amplitude cyclic endurance can be assessed for specimens operating at constant amplitude cyclic loading. However a method of assessing cyclic endurance for variable amplitude loading is desirable. In the first instance it is desirable to be able to classify the various seismic loading testing regimes that use progressively increasing amplitudes of displacement.

The proposed approach is that a Palmgren-Miner summation be used in which the proportion of quarter cycles required per displacement step relative to the constant amplitude endurance for cycles at that step be accumulated until the greatest step is reached at which the accumulated proportion of endurance is less than or equal to 1.0. This sets the structural ductility limit .

This is summarised in terms of ATC-24 cyclic loading in Table 1., based on the calculated ductility ratings in Tables 2 to 6 . This is illustrated in Figure 17 for an ATC-24 loading regime applied to the 300Plus steel with specific work of fracture $R_{c}=38 \mathrm{~kJ} / \mathrm{m}^{2}$.

The values for $\eta_{\mathrm{pM}}$ and the number of cycles $\mathrm{N}_{\mathrm{f}}$ to running fracture are within the same range as those found in cyclic testing reported by Kuwamura and Takagi [3] for a similarly proportioned bar in their Series 2 tests made from SN490 steels. This is very encouraging with respect to validating the approach taken with the use of specific work of fracture based measures of fracture toughness in what are very ductile materials.

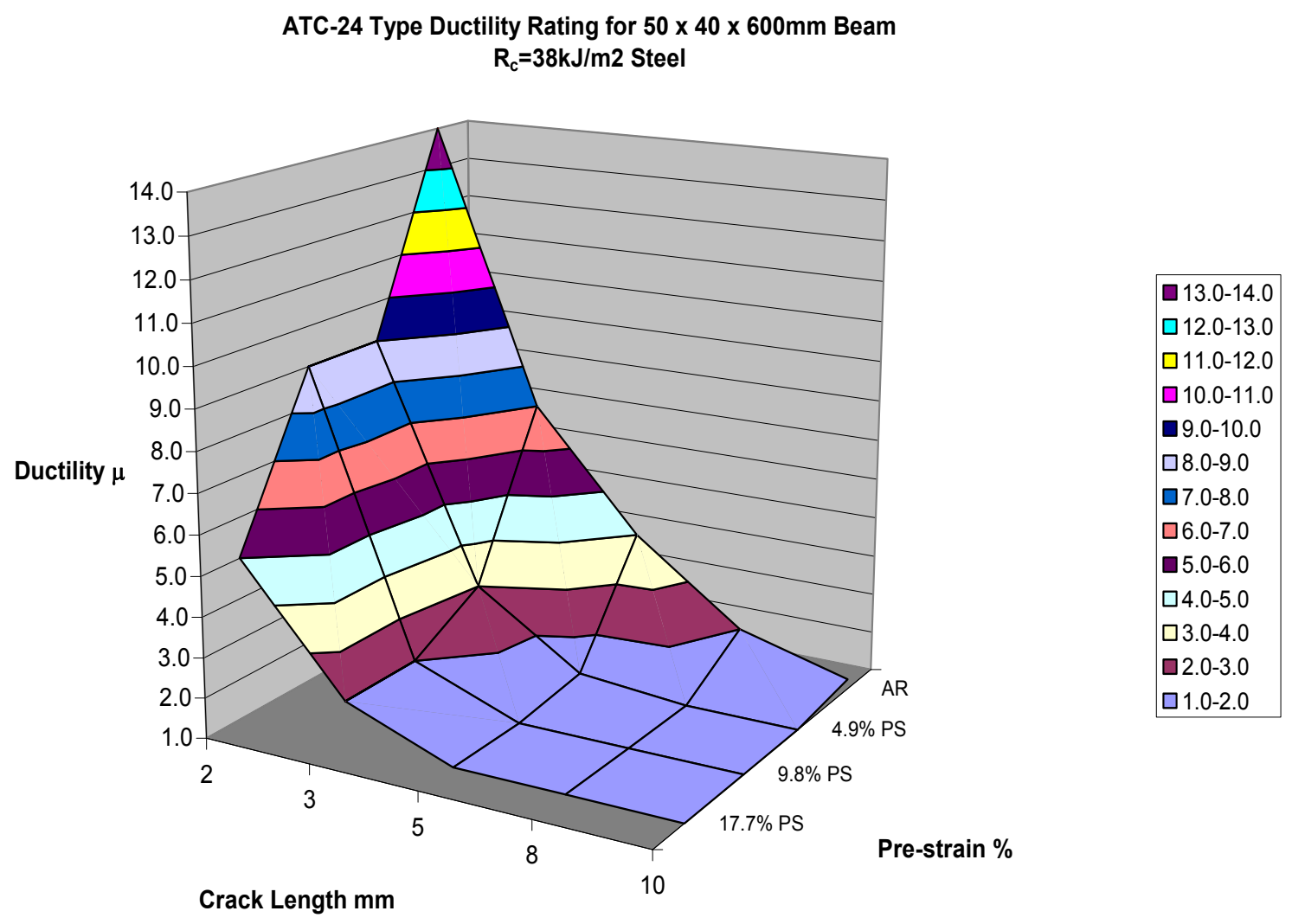

Figure 17. ATC-24 Loading Regime Cyclic Ductility Prediction for Varying Crack Length and \% Strain State 
Table 1. ATC-24 Loading Regime Cyclic Ductility Prediction

\begin{tabular}{|c|c|c|c|c|c|c|c|c|c|c|}
\hline Crack Length a mm & \multicolumn{2}{|c|}{2} & \multicolumn{2}{|c|}{3} & \multicolumn{2}{|c|}{5} & \multicolumn{2}{|c|}{8} & \multicolumn{2}{|c|}{10} \\
\hline Toughness Rc kJ/m² & 38 & 30 & 38 & 30 & 38 & 30 & 38 & 30 & 38 & 30 \\
\hline Monotonic Ductility $\eta_{\mathrm{pM}}$ & 192.0 & 97.6 & 52.6 & 33.4 & 20.4 & 12.5 & 7.4 & 3.8 & 4.5 & 2.2 \\
\hline Steel Pre-strain & \multicolumn{10}{|c|}{ ATC-24 Type Ductility Rating $\mu$} \\
\hline AR & 14.0 & 10.0 & 7.0 & 5.0 & 4.0 & 3.0 & 2.0 & 1.25 & 1.25 & 1.25 \\
\hline $4.9 \%$ PS & 9.0 & & 3.0 & & 1.25 & & 1.0 & & 1.0 & \\
\hline $9.8 \% \mathrm{PS}$ & 9.0 & & 2.0 & & 1.0 & & 1.0 & & 1.0 & \\
\hline $17.7 \%$ PS & 5.0 & & 2.0 & & 1.0 & & 1.0 & & 1.0 & \\
\hline
\end{tabular}

Table 2. M Series Bar ATC-24 Cyclic Endurance Surface for Varying Crack Lengths

As-Received M: $50 \times 40 \times 600 \mathrm{~mm}$ Bar: $R_{\mathrm{c}}=30 \mathrm{~kJ} / \mathrm{m}^{2}$

\begin{tabular}{|c|c|c|c|c|c|c|c|c|c|c|}
\hline Crack Length a mm & \multicolumn{2}{|c|}{2} & \multicolumn{2}{|c|}{3} & \multicolumn{2}{|c|}{5} & \multicolumn{2}{|c|}{8} & \multicolumn{2}{|c|}{10} \\
\hline Monotonic Ductility $\eta_{\mathrm{pM}}$ & \multicolumn{2}{|c|}{97.6} & \multicolumn{2}{|c|}{33.4} & \multicolumn{2}{|c|}{12.5} & \multicolumn{2}{|c|}{3.8} & \multicolumn{2}{|c|}{2.2} \\
\hline ATC-24 Ductility $\mu$ & \multicolumn{2}{|c|}{10.0} & \multicolumn{2}{|c|}{5.0} & \multicolumn{2}{|c|}{3.0} & \multicolumn{2}{|c|}{1.25} & \multicolumn{2}{|c|}{1.25} \\
\hline Plastic Ductility $\mu_{p}$ & $\mathrm{~N}_{f}$ & $12 / \mathrm{N}_{\mathrm{f}}$ & $\mathrm{N}_{\mathrm{f}}$ & $12 / \mathrm{N}_{\mathrm{f}}$ & $\mathrm{N}_{f}$ & $12 / \mathrm{N}_{\mathrm{f}}$ & $N_{f}$ & $12 / \mathrm{N}_{\mathrm{f}}$ & $\mathrm{N}_{f}$ & $12 / \mathrm{N}_{\mathrm{f}}$ \\
\hline 0.25 & 20818 & & 3474 & & 670 & & 89 & 0.135 & 35 & 0.347 \\
\hline 1.0 & 2055 & 0.006 & 339 & 0.035 & 64 & 0.188 & 8 & & 2 & \\
\hline 2.0 & 643 & 0.019 & 105 & 0.115 & 19 & 0.636 & 2 & & 1 & \\
\hline 3.0 & 325 & 0.037 & 52 & 0.230 & 9 & & 1 & & 1 & \\
\hline 4.0 & 200 & 0.060 & 32 & 0.380 & 5 & & 1 & & 1 & \\
\hline 5.0 & 137 & 0.088 & 21 & & 3 & & 1 & & 0 & \\
\hline 6.0 & 100 & 0.120 & 15 & & 2 & & 1 & & 0 & \\
\hline 7.0 & 30 & 0.398 & 4 & & 1 & & 0 & & 0 & \\
\hline 8.0 & 26 & 0.459 & 3 & & 1 & & 0 & & 0 & \\
\hline 9.0 & 23 & 0.523 & 3 & & 1 & & 0 & & 0 & \\
\hline Endurance Ratio & & 1.709 & & 0.760 & & 0.824 & & 0.135 & & 0.347 \\
\hline
\end{tabular}

Table 3 As-Received 300+ Bar ATC-24 Cyclic Endurance Surface for Varying Crack Lengths

As-Received 300+: $50 \times 40 \times 600 \mathrm{~mm}$ Bar: $R_{c}=38 \mathrm{~kJ} / \mathrm{m}^{2}$

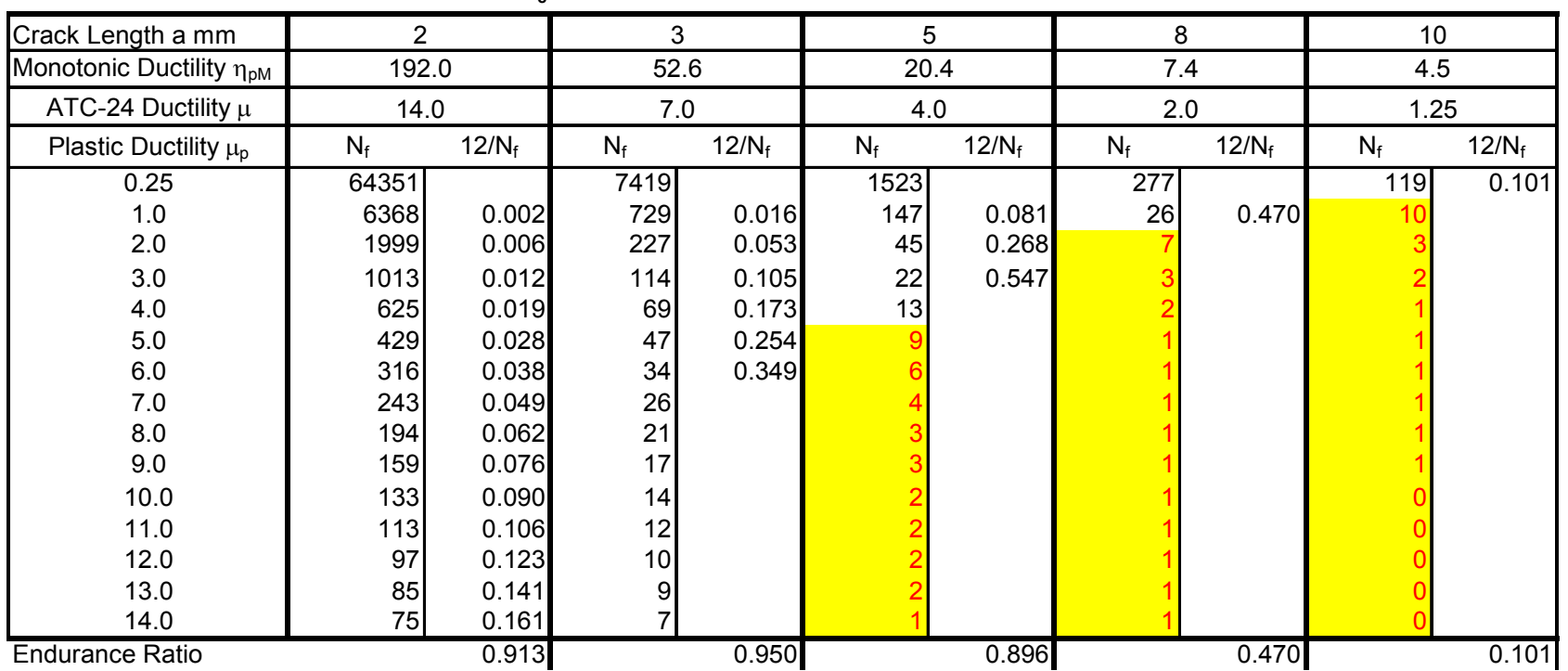


Table 4. 4.9\% Pre-Strained 300+ Bar ATC-24 Cyclic Endurance Surface for Varying Cracks $4.9 \%$ Pre-strained 300+: $50 \times 40 \times 600 \mathrm{~mm}$ Bar: $R_{\mathrm{c}}=38 \mathrm{~kJ} / \mathrm{m}^{2}$

\begin{tabular}{|c|c|c|c|c|c|c|c|c|c|c|}
\hline Crack Length a mm & \multicolumn{2}{|l|}{2} & \multicolumn{2}{|l|}{$\overline{3}$} & \multicolumn{2}{|l|}{5} & \multicolumn{2}{|c|}{$\overline{8}$} & \multicolumn{2}{|c|}{10} \\
\hline Monotonic Ductility $\eta_{\mathrm{pM}}$ & \multicolumn{2}{|c|}{90.0} & \multicolumn{2}{|c|}{16.6} & \multicolumn{2}{|l|}{1.6} & \multicolumn{2}{|c|}{0.7} & \multicolumn{2}{|c|}{0.7} \\
\hline ATC-24 Ductility $\mu$ & \multicolumn{2}{|c|}{9.0} & \multicolumn{2}{|c|}{3.0} & \multicolumn{2}{|c|}{1.25} & \multicolumn{2}{|c|}{1.0} & \multicolumn{2}{|c|}{1.0} \\
\hline Plastic Ductility $\mu_{p}$ & $N_{f}$ & $12 / \mathrm{N}_{\mathrm{f}}$ & $N_{f}$ & $12 / \mathrm{N}_{\mathrm{f}}$ & $N_{f}$ & $12 / \mathrm{N}_{\mathrm{f}}$ & $N_{f}$ & $12 / N_{f}$ & $N_{f}$ & $12 / \mathrm{N}_{\mathrm{f}}$ \\
\hline 0.25 & 18184 & & 1078 & & 20 & 0.609 & & & 4 & \\
\hline 1.0 & 1794 & 0.007 & 104 & 0.116 & 2 & & & & 1 & \\
\hline 2.0 & 561 & 0.021 & 31 & 0.384 & 1 & & & & 0 & \\
\hline 3.0 & 283 & 0.042 & 15 & & 1 & & & & 0 & \\
\hline 4.0 & 174 & 0.069 & 9 & & 0 & & & & 0 & \\
\hline 5.0 & 119 & 0.101 & 6 & & 0 & & & & 0 & \\
\hline 6.0 & 87 & 0.138 & 4 & & 0 & & & & 0 & \\
\hline 7.0 & 67 & 0.179 & 3 & & 0 & & & & 0 & \\
\hline 8.0 & 53 & 0.226 & 2 & & 0 & & & & 0 & \\
\hline 9.0 & 43 & & 2 & & 0 & & & & 0 & \\
\hline Endurance Ratio & & 0.784 & & 0.500 & & 0.609 & & 0.0 & & 0.00 \\
\hline
\end{tabular}

Table 5. 9.8\% Pre-Strained 300+ Bar ATC-24 Cyclic Endurance Surface for Varying Cracks 9.8\% Pre-strained 300+: $50 \times 40 \times 600 \mathrm{~mm}$ Bar: $\mathrm{R}_{\mathrm{c}}=38 \mathrm{~kJ} / \mathrm{m}^{2}$

\begin{tabular}{|c|c|c|c|c|c|c|c|c|c|c|}
\hline Crack Length a mm & \multicolumn{2}{|l|}{2} & \multicolumn{2}{|c|}{3} & \multicolumn{2}{|c|}{5} & \multicolumn{2}{|c|}{8} & \multicolumn{2}{|c|}{10} \\
\hline Monotonic Ductility $\eta_{\mathrm{pM}}$ & \multicolumn{2}{|c|}{79.8} & \multicolumn{2}{|c|}{8.3} & \multicolumn{2}{|c|}{0.9} & \multicolumn{2}{|c|}{0.7} & \multicolumn{2}{|c|}{0.7} \\
\hline ATC-24 Ductility $\mu$ & \multicolumn{2}{|c|}{9.0} & \multicolumn{2}{|c|}{2.0} & \multicolumn{2}{|c|}{1.0} & \multicolumn{2}{|c|}{1.0} & \multicolumn{2}{|c|}{1.0} \\
\hline Plastic Ductility $\mu_{\mathrm{p}}$ & $\mathrm{N}_{\mathrm{f}}$ & $12 / \mathrm{N}_{\mathrm{f}}$ & $\mathrm{N}_{\mathrm{f}}$ & $12 / \mathrm{N}_{\mathrm{f}}$ & $\mathrm{N}_{\mathrm{f}}$ & $12 / \mathrm{N}_{\mathrm{f}}$ & $\mathrm{N}_{\mathrm{f}}$ & $12 / \mathrm{N}_{\mathrm{f}}$ & $\mathrm{N}_{\mathrm{f}}$ & $12 / \mathrm{N}_{\mathrm{f}}$ \\
\hline 0.25 & 14877 & & 336 & & & & & & & \\
\hline 1.0 & 1467 & 0.008 & 31 & 0.384 & & & & & & \\
\hline 2.0 & 458 & 0.026 & 9 & & & & & & & \\
\hline 3.0 & 231 & 0.052 & 4 & & & & & & & \\
\hline 4.0 & 142 & 0.085 & 2 & & & & & & & \\
\hline 5.0 & 97 & 0.124 & 2 & & & & & & & \\
\hline 6.0 & 71 & 0.169 & 1 & & & & & & & \\
\hline 7.0 & 54 & 0.221 & 1 & & & & & & & \\
\hline 8.0 & 43 & 0.279 & 1 & & & & & & & \\
\hline 9.0 & 35 & & 1 & & & & & & & \\
\hline Endurance Ratio & & 0.964 & & 0.384 & & 0.00 & & 0.0 & & 0.00 \\
\hline
\end{tabular}

Table 6. 17.7\% Pre-Strained 300+ Bar ATC-24 Cyclic Endurance Surface for Varying Cracks

17.7\% Pre-strained 300+: $50 \times 40 \times 600 \mathrm{~mm}$ Bar: $R_{\mathrm{c}}=38 \mathrm{~kJ} / \mathrm{m}^{2}$

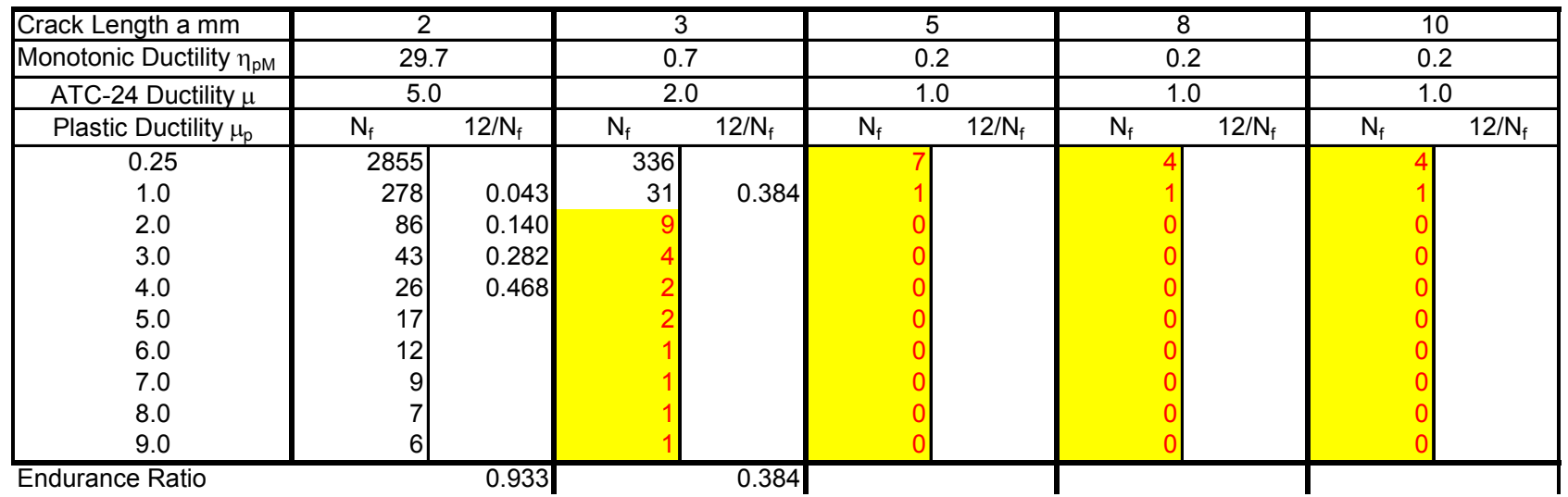




\section{CONCLUSIONS}

The application of Specific Work of Fracture concepts to deriving critical specific work of fracture $\mathrm{R}_{\mathrm{c}}$ values for ductile steels from CTOD specimens has proved to be useful, allowing a prediction of fracture behaviour for a range of crack depths and strain hardening conditions. The importance of using a Direct Current Potential Drop approach to assess crack growth characteristics during the CTOD tests is emphasised as this allows development of $\mathrm{R}$ curves related to crack area to be readily calculated throughout the test.

In conjunction with elastic and elasto-plastic finite element analyses of structural members the method allows a consistent and rational estimation of cracking load either pre- or post yielding. Limit state failure surfaces may be constructed for crack propagation loads, plastic hinge development loads and also for displacement to cracking. By using this approach to assess monotonic displacement ductility a wide range of structural configurations may potentially be analysed and assessed with respect to cyclic ductility capacity using Kuwamura's similitude relationship or the strain history approach. This is a significant benefit to structural engineering designers and researchers seeking to assess the ductile endurance of existing and new seismic resisting frames.

The combination of specific work of fracture and tensile stress-strain properties when incorporated into a finite element model allows useful prediction of fracture loads and member displacement behaviour. While the method appears valid for constant displacement amplitude behaviour a method of application for variable increasing amplitude loading cycles is proposed which utilises a Palmgren-Miner summation method. This allows ductility assessments in terms of cyclic test loading regimes to be assessed. A rain flow counting method is potentially applicable also to extend the approach to fully variable amplitude cyclic loading as commonly occurs in earthquakes. However no validation has been made of such an approach, although it seems reasonable.

A review of test results reported by Kuwamura and Takagi indicates that the values of monotonic and cyclic ductility predicted by the method proposed in this report are within the right range to be considered useful in a structural engineering assessment sense. Further calibration and refinement of the method therefore appears to be well justified.

\section{NOTATION AND SYMBOLS}

$\begin{array}{ll}\text { ATC-24 } & \text { Applied Technology Council cyclic testing guideline } \\ \mathrm{a} & \text { Crack length } \\ \mathrm{B} & \text { Breadth or thickness of a CTOD specimen; Proportionality constant } \\ \mathrm{B}_{\text {eff }} & \text { Effective section thickness of side-grooved CTOD specimen per BS7448.4 } \\ \mathrm{B}_{\mathrm{N}} & \text { Net section thickness of side-grooved CTOD specimen per BS7448.4 } \\ \mathrm{CTOD} & \text { Crack Tip Opening Displacement } \\ \mathrm{DCPD} & \text { Direct current potential drop method of monitoring crack growth. } \\ \mathrm{E} & \text { Youngs modulus } \\ \mathrm{F} & \text { Applied force to CTOD specimen } \\ \mathrm{G}_{\mathrm{c}} & \text { Critical strain energy to generate crack growth } \\ \mathrm{K}_{\mathrm{r}} & \text { Stress intensity at crack propagation derived from an R-curve for elastic fracture } \\ & \text { without extensive plastic flow. } \\ \mathrm{K}_{\mathrm{Rc}} & \text { Equivalent elastic stress intensity at fracture derived from an } \mathrm{R}_{\mathrm{c}} \\ \mathrm{K}_{\mathrm{Ic}} & \text { Critical stress intensity at the crack tip perpendicular to the crack propagation or I-I } \\ & \text { plane for elastic brittle cracking to initiate with minimal far field plasticity in the } \\ & \text { specimen. } \\ \mathrm{M}_{\text {os.hinge }} & \text { Over-strength plastic section capacity }\end{array}$




\begin{tabular}{|c|c|}
\hline $\mathrm{M}_{\mathrm{pl}}$ & Bending plastic section capacity \\
\hline $\mathrm{M}_{\mathrm{Rc}}$ & Critical cracking moment \\
\hline $\mathrm{M}_{\mathrm{y}}$ & Bending capacity calculated at first yield of the extreme fibres of the section \\
\hline $\mathrm{N}$ & Number of cycles under cyclic loading \\
\hline $\mathrm{N}_{\mathrm{f}}$ & Number of quarter cycles under cyclic loading to fracture \\
\hline Plane strain & $\begin{array}{l}\text { The stress condition at a particular location along a crack front in which the transverse } \\
\text { restraint is fully rigid, measured in terms of strain on the } 3-3 \text { plane } \varepsilon_{33}=0 \text {. }\end{array}$ \\
\hline Plane stress & $\begin{array}{l}\text { The stress condition at a particular location along a crack front in which the transverse } \\
\text { restraint in terms of stress on the 3-3 plane } \sigma_{33}=0 \text {. }\end{array}$ \\
\hline $\mathrm{R}_{\mathrm{c}}$ & $\begin{array}{l}\text { Fracture toughness of steel based on specific work of fracture at which a crack will } \\
\text { run without further energy input. }\end{array}$ \\
\hline $\mathrm{S}$ & Span between outer loading points in three point bend test \\
\hline SENB3 & Simply supported three point bend specimen \\
\hline SN490 & Japanese constructional grade of steel with nominal UTS of $490 \mathrm{MPa}$ \\
\hline $\mathrm{u}$ & Displacement \\
\hline $\mathrm{u}_{\mathrm{el}}$ & Elastic component of displacement \\
\hline $\mathrm{W}$ & Width of CTOD specimen \\
\hline $\mathrm{X}$ & Applied force \\
\hline Y & Stress intensity coefficient \\
\hline$\Delta \delta_{\mathrm{p}}$ & Half-cycle plastic displacement \\
\hline$\Delta \mathrm{K}$ & Change in stress intensity during cyclic loading \\
\hline$\delta_{\mathrm{c}}$ & Crack tip opening displacement at fracture \\
\hline$\delta_{\mathrm{pM}}$ & Total monotonic plastic displacement of an applied load at fracture \\
\hline$\eta_{\mathrm{p}}$ & Cumulative cyclic plastic displacement ratio at fracture \\
\hline$\eta_{\mathrm{pM}}$ & Plastic displacement ratio at fracture under monotonic load \\
\hline$\mu$ & Total displacement ductility amplitude \\
\hline$\mu_{\mathrm{p}}$ & Cyclic plastic displacement ductility amplitude \\
\hline$v$ & Poissons ratio \\
\hline$\Sigma \Delta \delta_{\mathrm{p}}$ & Cumulative absolute plastic cyclic displacement at fracture \\
\hline$\sigma_{\mathrm{fl}}$ & Flow stress \\
\hline$\sigma_{\mathrm{fr}}$ & Fracture stress \\
\hline$\sigma_{\mathrm{u}}$ & Ultimate tensile stress \\
\hline$\sigma_{\mathrm{y}}$ & Yield stress \\
\hline$\sigma_{\text {crit }}$ & Critical section stress at which fracture will occur \\
\hline$\tau_{\mathrm{y}}$ & Dislocation shear yield stress of a crystal \\
\hline
\end{tabular}

\section{REFERENCES}

[1] Hyland, C.W.K., Ferguson, W.G. and Butterworth, J.W., "Effects of Pre-strain and Aging on the Fracture Toughness of Australasian Constructional Mild Steel", Proceedings of Structural Integrity and Fracture 2004, Brisbane, 2004.

[2] Atkins, A.G. and Mai, Y.-W., "Elastic and Plastic Fracture: Metals, Polymers, Ceramics, Composites, Biological Materials", Ellis Horwood Limited, Chichester, 1985.

[3] Kuwamura, H., and Takagi, N., "Similitude Law of Prefracture Hysteresis of Steel Members", Journal of Structural Engineering, Vol. 130, No. 5, pp. 752-761, 2004.

[4] Knott, J.F., "Fundamentals of Fracture Mechanics", Cambridge University, 1973.

[5] Standards New Zealand, "Structural Loadings Standard: Earthquake", NZS1170.5, Wellington, 2005. 